\title{
ANÁLISE GEO-HISTÓRICA DA OCUPAÇÃO HUMANA E IMPACTO AMBIENTAL NO IGARAPÉ GRANDE, EM BOA VISTA-RR
}

\author{
Geo-historical analysis of human occupation and environmental impact on \\ igarapé Grande, in Boa Vista-RR
}

\author{
Lúcio Keury Almeida Galdino \\ Professor do Curso de Geografia da Universidade Estadual de Roraima \\ lkagaldino@yahoo.com.br \\ Adriano Lucena da Silva \\ Graduando do Curso de Geografia da Universidade Estadual de Roraima \\ adrianolucenadasilva1995@gmail.com \\ Gilcimar Maysonnave da Luz \\ Graduando do Curso de Geografia da Universidade Estadual de Roraima \\ gilcimarmaysonnave@hotmail.com \\ Gean Guilherme Ferreira de Paula \\ Graduando do Curso de Geografia da Universidade Estadual de Roraima \\ limagean84@gmail.com
}

Recebido: 15/08/2019

Aceito: 18/11/2019

RESUMO: Na sociedade roraimense são percebidas as transformações no espaço urbano que refletem na presença do homem, na mudança de sua forma, provocando ocupações desordenadas/irregulares nas margens dos corpos hídricos. Em Boa Vista-RR, o igarapé Grande é um dos maiores corpos hídricos e seu percurso encontra-se na mancha urbana. Partindo desta premissa, a presente pesquisa tem por objetivo estudar as consequências da ocupação antrópica analisada pelo viés Geo-histórico, bem como avaliar o processo de urbanização nas margens do referido igarapé. Na metodologia foram utilizadas técnicas de sensoriamento remoto com o processo de análise, vetorização e interpretação das imagens de satélite - Landsat 8, disponível no site do Serviço Geológico Norte Americano (USGS), Google Earth Pro, ainda utilizou-se do software Qgis 2.18 para elaboração/tratamento das cartas imagens. No que tange a pesquisa (in loco) foram analisadas as mudanças da biota, decorrentes do uso e ocupação do solo levando a crer que o processo de urbanização está afetando a dinâmica natural do corpo hídrico, em estudo.

Palavras-chave: Igarapé Grande; Urbanização; Impactos Ambientais; Roraima.

ABSTRACT: In the Roraima society, the transformations in the urban space are recognize that reflects in the presence of the man, in the change of its form, causing disordered/irregular occupations in the borders of the water body. In Boa Vista-RR, the igarapé Grande is one of the largest water courses and its route is in the urban area. Based on this premise, the present research purpose to study the consequences of the anthropic occupation analyzed by the Geo-historical bias, just like to evaluate the urbanization process on the banks of the referred stream. In the methodology were used remote sensing techniques with the process of analysis, vectorization and interpretation of satellite images - Landsat 8 , available on the site of the North American Geological Survey (USGS), Google Earth Pro, and still used the software Qgis 2.18 for elaboration/treatment of the letters-images. In reference of the research (in

REVISTA GEONORTE, V.10, N.36, p.01-16, 2019.

(ISSN 2237-1419)

DOI: 10.21170/geonorte.2019.V.10.N.36.A01.16 
ANÁLISE GEO-HISTÓRICA DA OCUPAÇÃO HUMANA E IMPACTO AMBIENTAL NO IGARAPÉ GRANDE, EM BOA VISTA-RR.

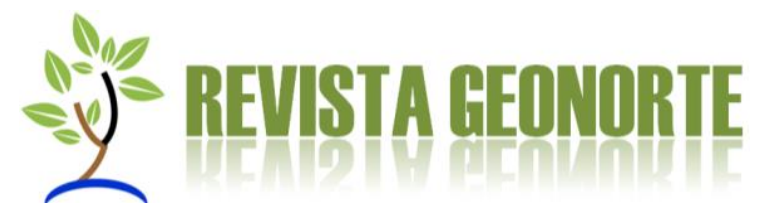

loco) the biota changes were analyzed, resulting to the land use and occupation, leading to the believe that the urbanization process is affecting the natural dynamics of the water body, under study.

Keywords: Igarapé Grande; Urbanization; Environmental Impacts; Roraima.

\section{INTRODUÇÃO}

O fenômeno humano da ocupação das margens dos cursos d'água não é recente, ao longo da História da Humanidade observa-se que, por questões básicas de sobrevivência como: a sede, a alimentação e as relações comunitárias (através da lógica do uso pelas vias hídricas), o homem nos seus anseios promove a ocupação do espaço e transforma-o, gerando impactos no decorrer do tempo, de forma gradativa e acumulativa.

Partindo dessa premissa, a construção do território se forma a partir do espaço e é o resultado de uma relação conduzida por agentes/atores (re) produtores que realizam seus anseios e suas "necessidades" nas perspectivas: social (de dominação), cultural (perda de identidade) e econômico (exploração das riquezas), revelado na atualidade com a ocupação humana em áreas naturais.

No que se refere às questões de áreas urbanas, pode-se elencar que é relevante a relação harmônica entre as políticas públicas e a sociedade em geral, pois os processos de produção socioespacial geram os mais diversos impactos negativos, dentre eles: ambientais; sociais; econômicos e culturais (RAFFESTIN, 1993).

Partindo desse pensamento, é possível entender as mudanças que ocorrem no meio ambiente que está intrinsecamente ligada às diversas questões sociais. Nesse entendimento, Veras (2009) enfatiza que, a produção do espaço urbano de Boa Vista é o resultado de uma inter-relação entre ações sociais, econômicas e políticas, acumuladas através do tempo no espaço.

$\mathrm{Na}$ atual conjuntura social roraimense são percebidas as transformações dentro da malha urbana (da Capital), que reflete na presença do homem na mudança de sua forma, provocando ocupações desordenadas/irregulares. Nessa perspectiva, segundo Agostinho (2016, p.132) pode-se afirmar que, "os problemas ambientais mais sérios de Roraima concentram-se na área urbana de Boa Vista, principalmente nos bairros periféricos e em suas inúmeras ocupações irregulares".

Neste sentido, o igarapé Grande é um dos maiores corpos hídricos do município de Boa Vista, entretanto cabe destacar que seu percurso encontra-se na mancha urbana. Partindo desta premissa, a presente pesquisa tem por objetivo estudar as consequências da ocupação antrópica analisada pelo viés Geo-histórico, bem como avaliar o processo de urbanização nas margens do referido igarapé. 
ANÁLISE GEO-HISTÓRICA DA OCUPAÇÃO HUMANA E IMPACTO AMBIENTAL NO IGARAPÉ GRANDE, EM BOA VISTA-RR.

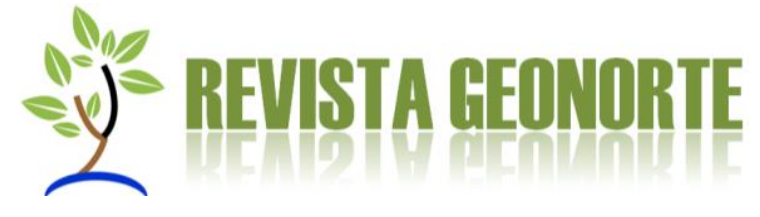

\section{MATERIAIS E MÉTODOS}

Para a realização da pesquisa destacaram-se dois pontos, selecionados pelos pesquisadores, que estão em uma área limítrofe dividindo os bairros São Bento e Centenário em Boa Vista-RR, na zona oeste do município, que não foge à regra desta área citadina emergida de ocupações desordenadas e irregulares. Dessa forma, o processo de urbanização tem degradado de maneira notória o corpo hídrico, principalmente, por conta da existência de uma Estação de Tratamento de Esgoto (ETE) às suas margens, que lançam seus efluentes diretamente no igarapé.

No que se remete ao desenvolvimento da pesquisa foram utilizadas técnicas de sensoriamento remoto com o processo de análise, vetorização e interpretação das imagens de satélite - Landsat 8, disponível no site do Serviço Geológico Norte Americano (USGS), Google Earth Pro, ainda utilizou-se do software Qgis 2.18 para elaboração/tratamento das cartas imagens. Além disso, em trabalho de campo desenvolveu-se uma análise da área com objetivo de obter medidas da calha, do trecho do igarapé Grande.

É relevante informar que a pesquisa fora desenvolvida no decorrer do semestre letivo de 2019.1, na disciplina de Hidrografia, do curso de Licenciatura em Geografia da Universidade Estadual de Roraima - UERR, e que se dividiu em três etapas, são elas: i) acadêmica (leituras e discussões de referências bibliográficas sobre a temática da pesquisa - impactos ambientais, ocupações irregulares e hidrografia; ii) visita técnica in loco da pesquisa e; iii) elaboração do relatório para apresentação como resultado final da disciplina de Hidrografia.

Os materiais utilizados na pesquisa foram: a) câmera fotográfica 12 megapixels para realizar registros de imagens obtidas durante a visita técnica; b) Sistema de Posicionamento Global (GPS) - modelo Garmimmap76CS - para elaboração dos georreferenciamentos da área e; c) fita métrica para realizar da medição do corpo hídrico no sentido de possibilitar a mensuração da APP.

Portanto, na área de estudo existem construções de habitações humanas, na Área de Preservação Permanente (APP) ripária, que nos últimos anos vem transformando a natureza ocasionando a retirada da mata ciliar.

Contudo, a cobertura vegetal vem sofrendo intensos impactos decorrentes do processo de urbanização, cabendo ressaltar que o poder público corrobora nesse quesito implantando obras públicas como, a rede de saneamento básico onde as obras de drenagem passam pelas margens do corpo hídrico. Corroborando, Staevie (2011, p. 78) revela que a "expansão espacial forjada num amálgama de interesses entre o Estado e o capital, que, na sua lógica de autorreprodução, acaba por determinar a configuração urbana de mais esta cidade da Amazônia brasileira". 
ANÁLISE GEO-HISTÓRICA DA OCUPAÇÃO HUMANA E IMPACTO AMBIENTAL NO IGARAPÉ GRANDE, EM BOA VISTA-RR.

\section{RESULTADO E DISCUSSÕES}

\section{Breve análise do estado de Roraima}

O Estado de Roraima possui sua etimologia linguística, na formação da sua palavra, conectada com a questãocultural indígena, o que deriva do termo Roro-imã, onde possuem diferentes significados (GALDINO, 2017a). Nessa perspectiva, Roraima (2009) corrobora afirmando que a gênese da palavra, em sua lingua Macuxi, por exemplo, significa Monte Verde e para os índios Pemón e Taurepang, quer dizer Mãe dos Ventos.

Roraima encontra-se no extremo norte do território brasileiro e estende-se em latitude

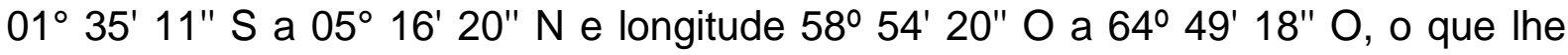
proporciona a uma peculiaridade em possuir $80 \%$ do seu território no hemisfério Norte. Cabe ressaltar que nesse território encontra-se o ponto extremo norte do Brasil, o Monte Caburaí (GALDINO, 2018).

Conforme Galdino (2017a), o estado compreende-se numa área total de 224.298,980 $\mathrm{km}^{2}$, estabelecendo fronteira tripartite internacional (Brasil - Venezuela - Guiana), com seus limites: na porção norte e noroeste, $958 \mathrm{~km}$ de fronteira (Brasil - Venezuela); ao leste, 964 km de fronteira (Brasil - Guiana); ao Sudeste, limita-se com o Pará e; Sul e Oeste, com o Amazonas, como mostra a (Figura 01).

Por conseguinte, o território roraimense possui uma área correspondente a 2,4\% do território brasileiro e, aproximadamente, $6 \%$ da Região Norte. Ainda é destaque por estar, substancialmente, acima da linha do Equador e sua capital, Boa Vista, encontrase totalmente, no hemisfério Norte (GALDINO, 2017b). 


\section{$2 y$ REVISTA GEONORTE}

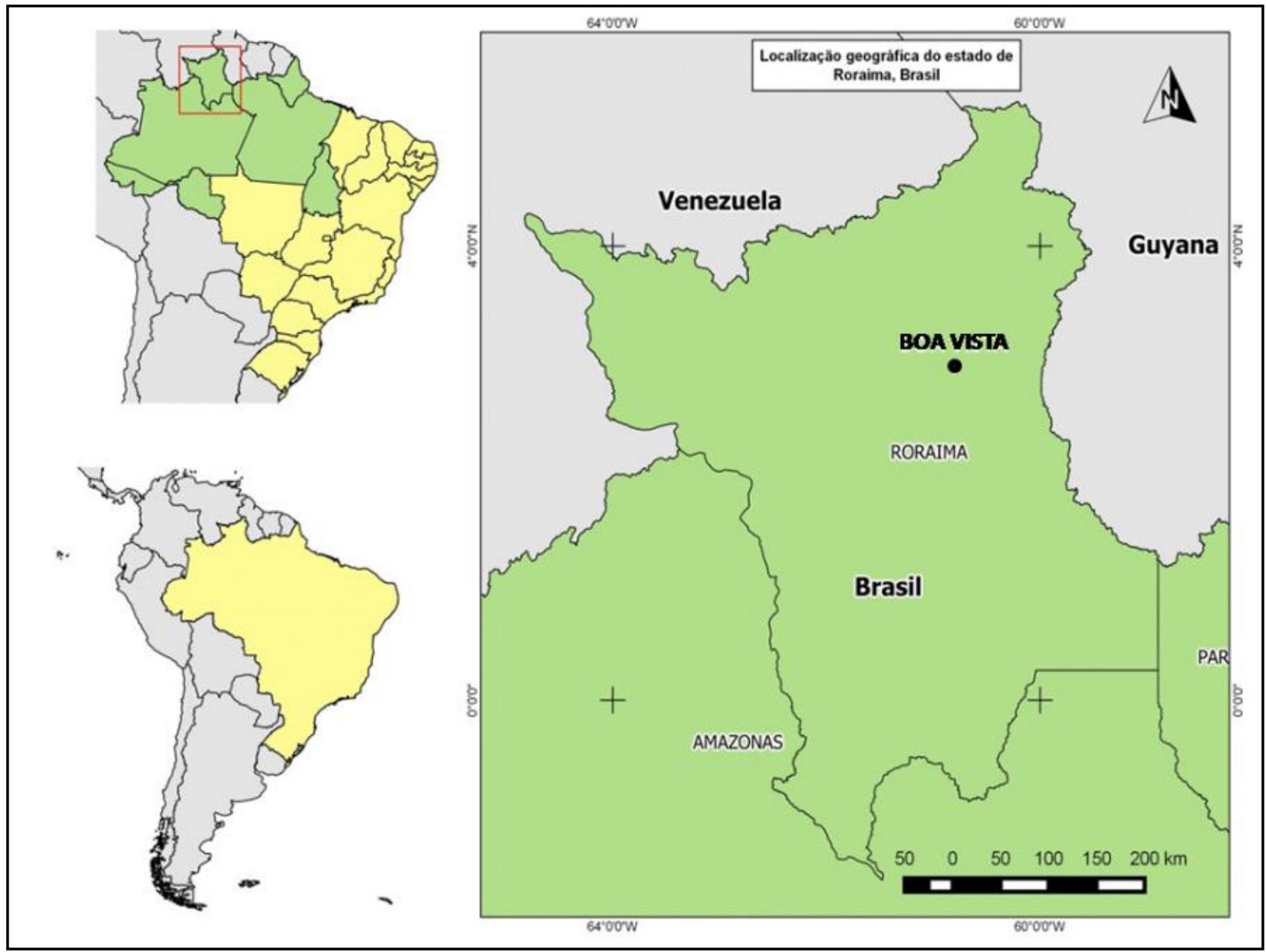

Figura 01: Localização geográfica do município de Boa Vista-RR. Fonte: IBGE, 2015.

Elaborado por Galdino, 2017b.

\section{Breve análise Geo-histórica de Roraima: ocupação humana e o desenvolvimento da cidade}

Para entender a formação do território roraimense, faz-se necessário conectar ao pretérito para que se justifiquem as mudanças apresentadas no espaço urbano no presente. Assim, cabe analisar/compreender o homem agindo e transformando o espaço ao longo do tempo, discutido na perspectiva Geo-histórica (BRAUDEL, 1990).

Portanto, Galdino (2017b) na obra Roraima: da colonização ao Estado faz um recorte geo-histórico delineado em três "cenas", assim batizada pelo autor, são elas: a) a Fazenda Boa Vista do Rio Branco (1830); b) a criação da Freguesia Nossa Senhora do Carmo (1858) e; c) a criação da Vila (Município) Boa Vista do Rio Branco (1890). Esses períodos apresentam a gênese da formação/ocupação do espaço urbano, caracterizados e legitimados pela introdução da economia voltada à pecuária bovina,onde favoreceu uma corrente migratória de indivíduos que assolados pela pobreza, e oriundos das regiões nordeste e norte, foram para antiga região do Rio 
ANÁLISE GEO-HISTÓRICA DA OCUPAÇÃO HUMANA E IMPACTO AMBIENTAL NO IGARAPÉ GRANDE, EM BOA VISTA-RR.

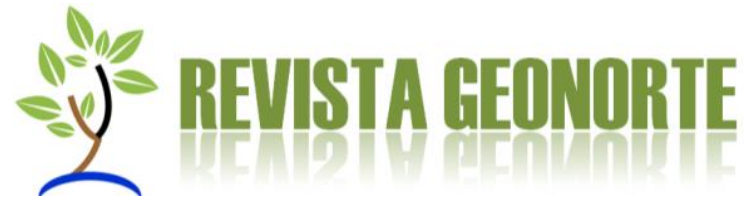

Branco que hoje forma a sociedade roraimense juntamente com os povos originários - os indígenas - que se faziam presentes dentro do contexto da premissa, sociológica/antropológica,na formação da região do Rio Branco.

Em síntese, dentro da questão espaço-tempo, entre 1890 a 1943 a ocupação (índios e não-índios) e estruturação (equipamentos urbanos, casas, obras de infraestrutura, etc) no espaço urbano em Boa Vista do Rio Branco foi de forma tímida. Justificando, Galdino (2017b) salienta que a cidade apresentara um cenário precário e preocupante com relação às condições subumanas, onde: concentravam-se as residências denominadas de mocambos (Figura 02) e poucas casas de alvenarias, com pouquíssimas habitações com infraestrutura sanitária; a população era subnutrida, uma alimentação com base na carne bovina, caça ou pesca e farinha e, consecutivamente; uma população doente onde a malária, tuberculose, sífilis, verminoses, dentre outras doenças assolavam a população viventena década de 1940, que contabilizava aproximadamente05 (cinco) mil habitantes na cidade.

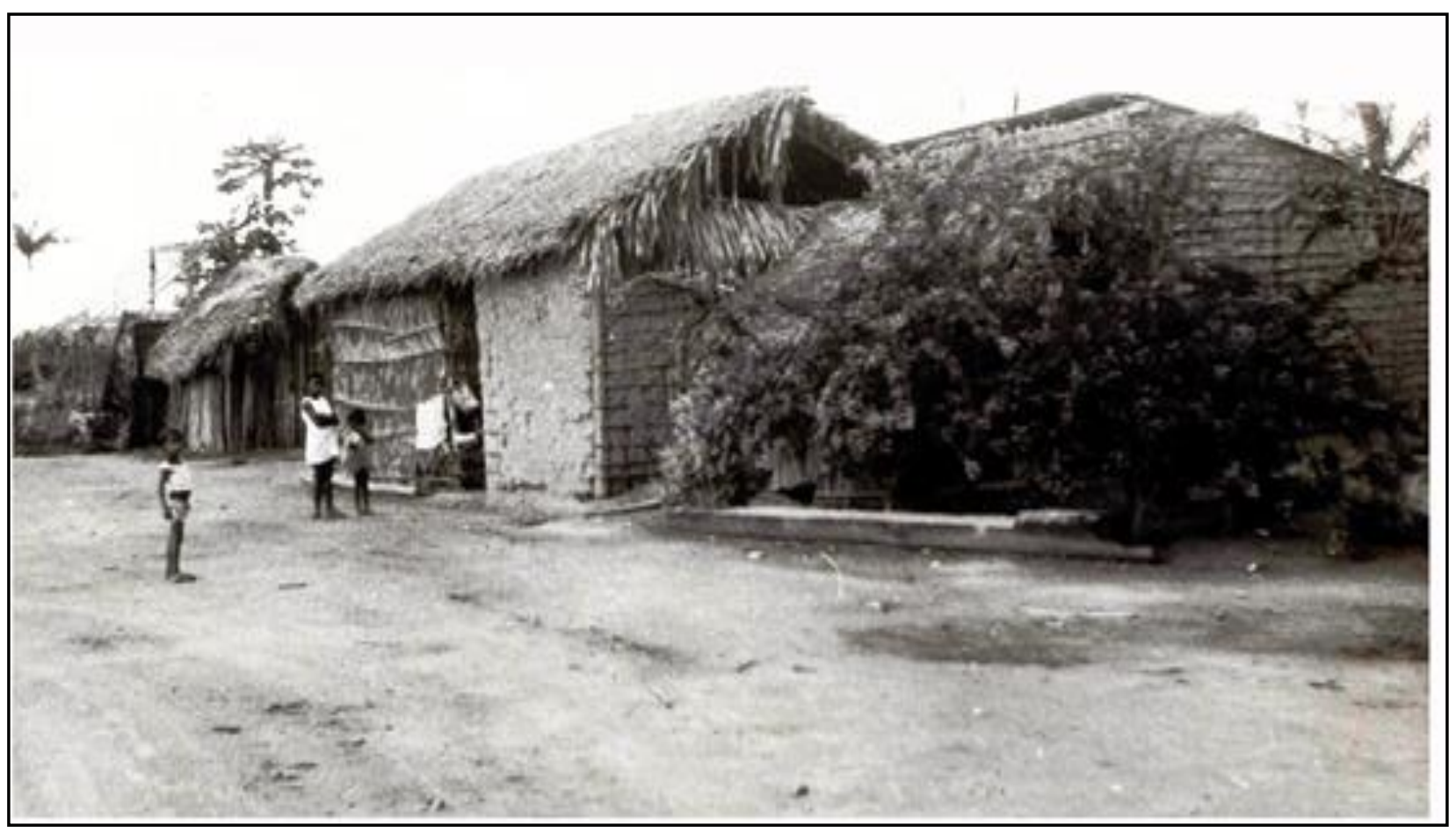

Figura 02: Tipo de residência da cidade de Boa Vista do Rio Branco (Déc. 1940). Fonte: Veras, 2009.

Nesse sentido, acredita-se que o município de Boa Vista do Rio Branco por se fazer distante de Manaus (Capital) alinhado com as dificuldades de acesso, não era "foco" dos interesses políticos e econômicos do Estado do Amazonas. Contudo, em 1943, o então Presidente Getúlio Vargas cria o Arquipélogo Fernando de Noronha e 05 (cinco) Territórios Federais, que foram: Ponta Porã (desmembrado do Mato Grosso), Iguassú (do Paraná), Guaporé (do Amazonas e Mato Grosso, atualmente Estado de 
Rondônia); Amapá (do Pará) e; Território Federal do Rio Branco (do Amazonas, hoje Estado de Roraima) de acordo com o Decreto-Lei $\mathrm{n}^{\circ}$ 5.812, instituído as novas unidades federais.

Com a criação do Território Federal do Rio Branco (TFRB) emerge a preocupação de proporcionar uma nova forma no espaço urbano de Boa Vista (Capital do TFRB), tendo em vista os problemas que ali se encontravam. O então Governador, Capitão Ene Garcez dos Reis, forma uma equipe liderada pelo engenheiro Darcy Aleixo Derenusson para planejar e estruturar os novos traçados urbanísticos à cidade de Boa Vista que no total, segundo Pavani e Moura (2007) foram mais de mil plantas desenvolvidas para detalhar o projeto que organizava a capital do TFRB.

Ainda, corroborando Galdino (2017b, p. 60) revela que:

O engenheiro Derenusson junto com sua equipe, no período de 1944 a 1946, inspirou-se, provavelmente, nas cidades de Belo Horizonte e Goiânia para projetar Boa Vista que, em formato de leque, ruas e avenidas largas em radial marcaram um novo modelo de espaço urbano na Amazônia.

A edificação da "nova" Boa Vista se estendeu durante as décadas de 1940 a1960 levando em consideração os estudos e planejamentos ocorridos durante a gestão do primeiro governador do TFRB. É relevante entender que apesar das mudanças políticas, eleições e sucessões no governo federal, a determinação em construir a "nova" Boa Vista continua e conjuntos habitacionais e equipamentos urbanos são criados (GALDINO, 2017b). Dessa forma, passou-se a incorporar uma nova roupagem espacial na paisagem urbana, onde "a dinâmica socioespacial passa por uma transformação estrutural em que mantém uma íntima ligação com as formas" (VERAS, 2009, p. 103).

Contudo, cabe destacar que enquanto as mudanças espaciais ocorriam na capital, novas estratégias foram pensadas para promover uma ocupação e expansão populacional no território federal, o que levou o Governo do TFRB, em 1944, a promover a criação da Colônia Fernando Costa que na época foi o marco na tentativa de colonizar a parte sul-florestal do território, e que ao longo das décadas de 1950 a 1970 novos projetos de colonização e assentamento foram desenvolvidos (GALDINO, 2017b).

Durante o período da Ditadura Militar no Brasil, o governo passa a dar novos olhares à Região Norte e inicia um processo de desenvolvimento vislumbrando a economia $\mathrm{e}$ a sociedade, respectivamente, a modernização/industrialização e a urbanização/ocupação. Nessa perspectiva, durante as duas primeiras décadas de governo militar (1960 e 70), o Território Federal de Roraima (TFR), criado em 1962, se insere no circuito das transformações de infraestrutura rodoviária ao desenvolver obras, como as: BR 174 (ligando Manaus a Boa Vista), BR 210 (Perimetral Norte, corta o sul do estado de leste a oeste) e BR 401 (liga Boa Vista ao município de Bonfim). Com o advento das rodovias, o governo do TFR atrai uma corrente migratória, principalmente de famílias nordestinas, onde as políticas públicas agrárias 
ANÁLISE GEO-HISTÓRICA DA OCUPAÇÃO HUMANA E IMPACTO AMBIENTAL NO IGARAPÉ GRANDE, EM BOA VISTA-RR.

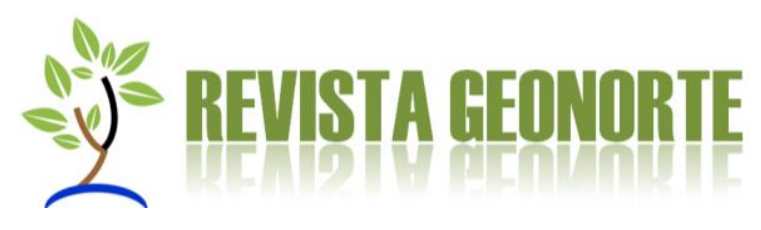

voltavam-se à infraestrutura econômica e social básica, prometendo qualidade de vida aos migrantes, lotes rurais, incentivos fiscais e financiamentos para desenvolvimento da terra. Esse período marca "uma nova etapa na colonização e ocupação demográfica de Roraima" (VALE, 2005, p. 80).

Segundo Galdino (2017b) foranos anos 1980 a 1991 que um boom demográfico ocorre no território e à população passa de 79.121 para 217.583 habitantes, um crescimento de $175 \%$. Nesse período, a política agrária é comprometida e um movimento migratório interno do território é ocasionado, o êxodo rural em Boa Vista cresce e se soma, em 1991, com o fechamento dos garimpos (decretado pelo governo federal) resultando no crescimento da cidade de forma desordenada e se formaram, pela primeira vez, bairros periféricos, até então inexistente (VALE, 2005).

Nesse período, o governo utilizou-se de uma política chamada de "paternalismo local" e iniciou a doação de lotes urbanos à população migrante e, dessa forma, surgem novos bairros como: Liberdade; Buriti, Caimbé; Asa Branca (Figura 03), além de doar materiais para construção de residências, alimentos básicos, entre outros (VALE, 2005).

O momento em Boa Vista foi marcado por um aumento considerável da densidade demográfica urbana, e os "novos bairros" surgem sem a mínima condição de infraestrutura básica. Porém, cabe ressaltar que o migrante, além de adquirir seu lote na área urbana, também recebia outro na área rural (VERAS, 2009 e VALE, 2005). Portanto, a capital de Roraima vislumbrou um crescimento urbano desordenado se expandindo em direção à zona oeste; e um princípio de dispersão após o rio Branco, década de 1990, com o loteamento - cidade Santa Cecília, que se tornou um bairro satélite de Boa Vista, porém localizado no município de Cantá. 


\title{
2 REVISTA GEONORTE
}

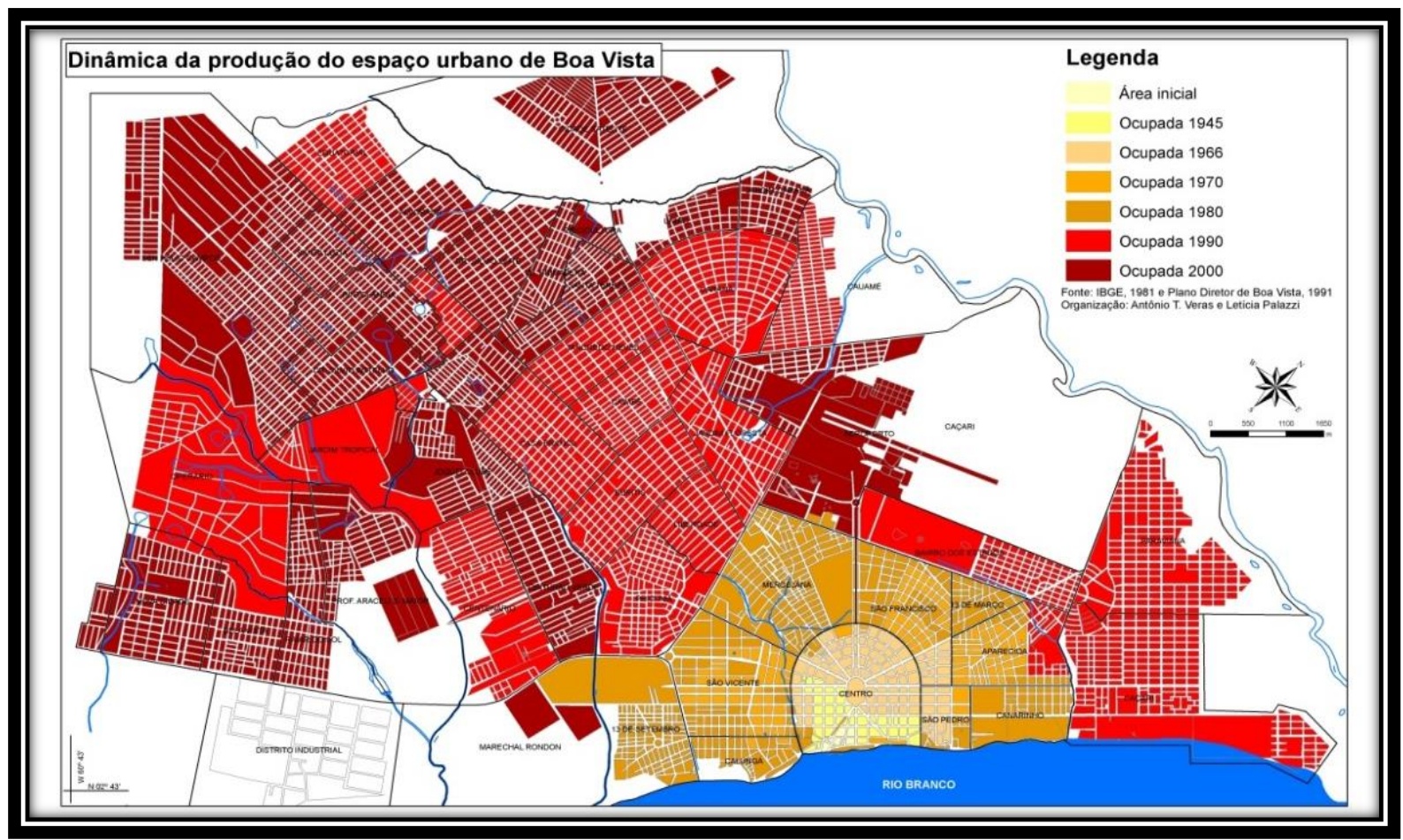

Figura 03: Plano Diretor de Boa Vista - 2006. Fonte: Veras, 2009.

\section{RESULTADOS}

Sobre a questão do uso da água, na antiguidade, as civilizações localizavam-se nas proximidades dos rios e estes associavam ao desenvolvimento do homem, no que se refere a sua sobrevivência e a sua cultura. Pode-se exemplificar, dentro da escala de espaço-tempo, a região da Mesopotâmia onde diversas civilizações se fixaram às margens dos rios Tigre e Eufrates na obtenção de terras férteis que, simbolicamente, era sinônimo de poder (GALDINO, 2018).

Para Galdino (2018, p. 40), na contemporaneidade, "discute-se sobre o planejamento e a gestão dos recursos hídricos e logo surge o referencial global, da rede hidrográfica da região amazônica, pois esta é considerada uma das principais reservas de água doce do planeta". Sobre a rede hidrográfica amazônica, Evangelista et al., (2008, p. 144) corrobora afirmando que:

\begin{abstract}
Sabe-se ainda que sua exuberância relaciona-se aos altos volumes de chuvas precipitados sobre ela. Estas características, por outro lado, acabam por mascarar peculiaridades existentes nas diferentes áreas, resultado dos diferentes volumes precipitados e pela sua sazonalidade. A baixa densidade de pontos de monitoramento pluviométricos e fluviométricos, em especial a inexistência de séries históricas, somado a demanda de interpretação dos dados já existentes, representam um dos grandes desafios na Amazônia. A bacia do rio Branco, subafluente do rio Amazonas, reflete bem esta problemática.
\end{abstract}


Conforme Galdino (2018), no arranjo dessa relevante bacia hidrográfica, apresentase a bacia do rio Branco, um afluente esquerdo do rio Negro, que se torna subafluente do rio Amazonas. Assim, o rio Branco e sua bacia hidrográfica com $204.640 \mathrm{~km}^{2}$ drenam praticamente todo o estado de Roraima e têm sua hipsometria que revela em sua maior parte abaixo da cota de 500 metros, e com uma altitude, em média, de 309 metros, apresentando importantes variações na sua morfologia, pluviosidade e vegetação (RORAIMA, 1992 apud EVANGELISTA et al., 2008).

Segundo SEPLAN-RR (2013), o estado roraimense tem 24 bacias hidrográficas. Nesse sentido, o rio Branco nasce na confluência dos rios Uraricoera e Tacutu, e é considerado um dos principais rios do Estado passando pelos limites municipais de (Bonfim, Boa Vista, Cantá, Iracema, Caracaraí e Rorainópolis), a sua presença, paralelamente, influencia na questão socioeconômica e cultural.

No que se remete a questão hidrográfica da capital do estado de Roraima, Boa Vista, Cavalcante Martins, Santos e Souza (2014, p. 44) revela que a sua hidrografia é composta por "seis bacias hidrográficas, o Rio Branco e seus afluentes, onde o rio Cauamé e o lgarapé Grande são os principais" e existem "vários igarapés e lagoas de natureza permanentes ou temporárias".

Nesse contexto, cabe destacar que os processos de urbanização estão afligindo diretamente aos ambientes que deveriam ser preservados e não impactando exponencialmente 0 meio ambiente, principalmente nos bairros periféricos do município de Boa Vista - RR, onde segundo Agostinho (2016, p.263) "os problemas ambientais mais sérios de Roraima concentram-se na área urbana de Boa Vista, principalmente nos bairros periféricos e em suas inúmeras ocupações irregulares".

Portanto, neste trabalho de campo foram analisados dois pontos específicos no curso urbano do igarapé Grande. Entende-se que esse estudo é relevância em suas análises, pois a priori existem modificações no meio físico decorrentes das ações antrópicas, que tratou-se em verificar dois pontos do trecho do igarapé, são eles: Ponto 1 (P1) com coordenadas geográficas (latitude $02^{\circ} 47^{\prime} 43^{\prime \prime} \mathrm{N}$ e longitude $60^{\circ} 42^{\prime}$ $71^{\prime \prime)}$ e Ponto 2 (P2) com coordenadas geográficas (latitude $02^{\circ} 47^{\prime} 40^{\prime \prime} \mathrm{N}$ e longitude 60 42' 63" O), ambos os pontos estão localizados em APP que segundo o Código Florestal são áreas protegidas, cobertas ou não por vegetação nativa, com a função ambiental de preservar os recursos hídricos, a paisagem, a estabilidade geológica, a biodiversidade, facilitar o fluxo gênico de fauna e flora, proteger o solo e assegurar o bem estar das populações humanas (BRASIL, 1965).

No desenvolvimento da pesquisa fora elaborada uma carta imagem (Figura 04) que demonstra pela escala espaço-tempo (ano de 2018 e 2019), as modificações ocorridas nas áreas estudadas (P1 e P2), cabendo revelar que ocorreram transformações no meio físico decorrentes do processo de urbanização. Portanto, a carta imagem apresenta uma divisão em 03 (três) recortes espaciais denominados de A, B e C, abrangendo as seguintes informações: A - destacam-se os pontos estudados; $B$ - revela uma imagem do mês de maio de 2018 , onde os pontos P1 e P2 apresentavam resquício vegetacional na margem do igarapé e; C - revela uma 
ANÁLISE GEO-HISTÓRICA DA OCUPAÇÃO HUMANA E IMPACTO AMBIENTAL NO IGARAPÉ GRANDE, EM BOA VISTA-RR.

imagem do mês de maio de 2019, onde o ponto P1 apresenta um estágio maior de degradação decorrente ao processo de instalação da rede de drenagem pluvial, e o P2 ainda apresenta resquício de vegetação ripária.

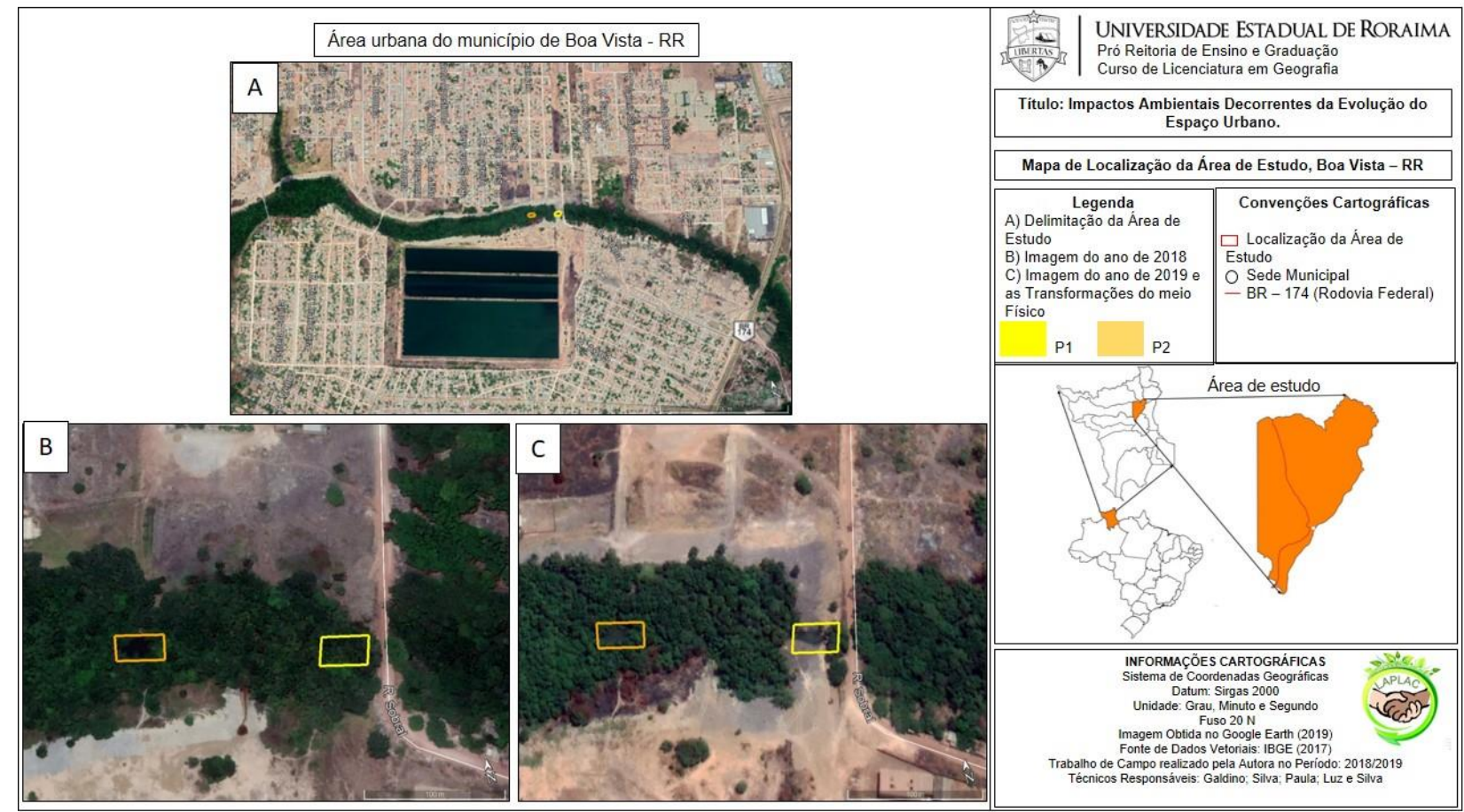

Figura 04: Carta imagem das alterações ocorridas no período de um ano. Fonte: Elaborada pelos autores, 2019.

Assim, a pesquisa compreende a entender os impactos ambientais ocasionados pelas ocupações irregulares e os processos de urbanização, conforme mostra na carta imagem do (P1) que destaca de forma clara os impactos decorrentes do processo de urbanização demonstrado no (Figura 05). 
ANÁLISE GEO-HISTÓRICA DA OCUPAÇÃO HUMANA E IMPACTO AMBIENTAL NO IGARAPÉ GRANDE, EM BOA VISTA-RR.

\section{DUe REVISTA GEONORTE}

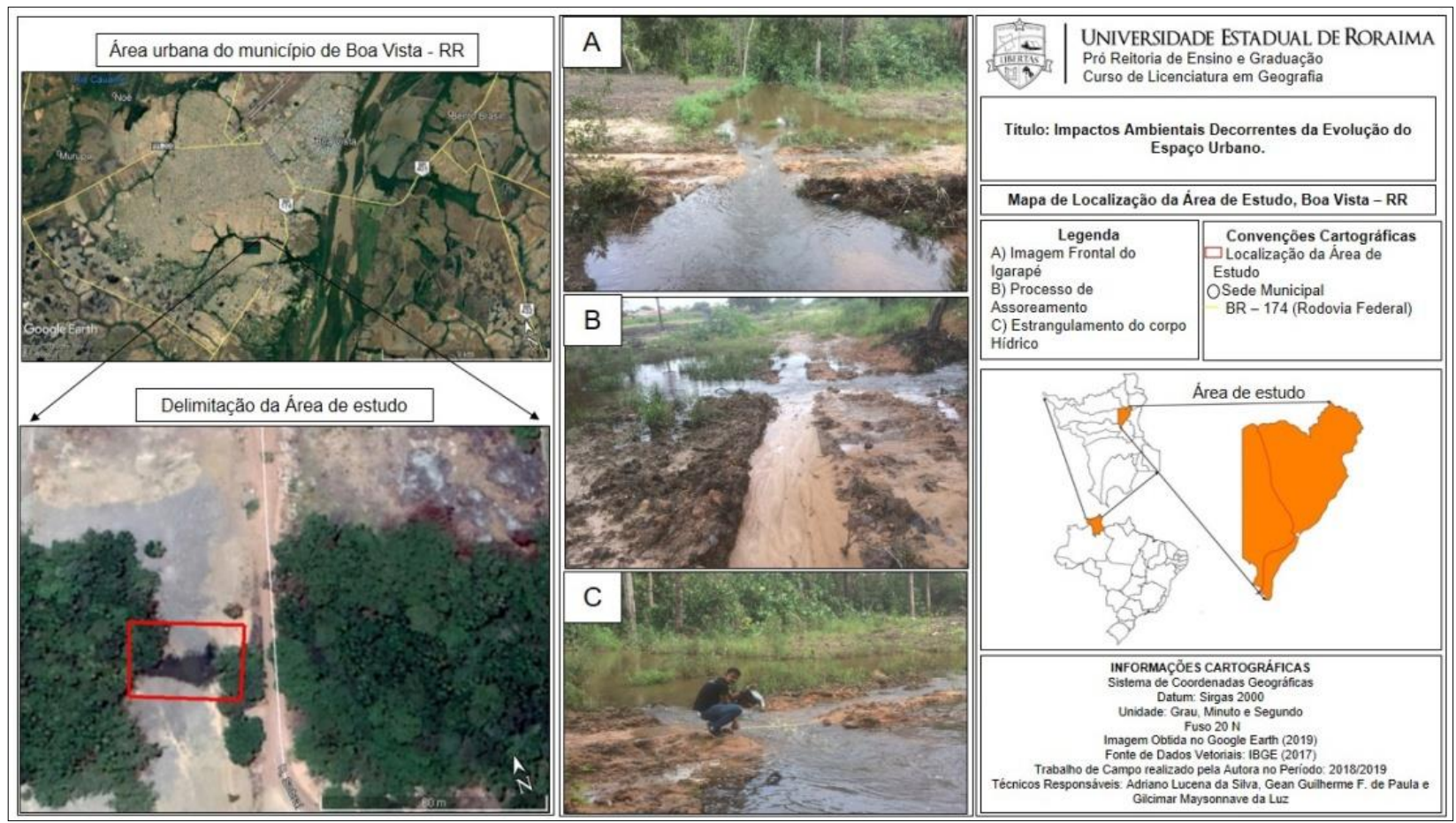

Figura 05: Carta imagem do P1.Fonte: Elaborada pelos autores, 2019.

Nota-se uma retirada total da cobertura vegetal da área delimitada, ocasionando inúmeros processos que impactam diretamente o ambiente natural, a exemplo de assoreamento do corpo hídrico, estrangulamento do igarapé, diminuição do leito natural, perda de vegetação nativa, dentre outros.

Todos esses impactos elencados foram ocasionados pelo processo de urbanização na cidade de Boa Vista, não respeitando a legislação vigente que protege essas APP, pois segundo o Código Florestal o curso regular deste corpo hídrico é superior a 10 metros, o que deveria ter uma área de preservação da mata ciliar, de 50 metros.

$\mathrm{Na}$ carta imagem do (P2) observar-se a presença de resquícios de vegetação ciliar, diferentemente do (P1) que está totalmente degradada. Todavia essa vegetação não atende ao Código Florestal que determina 50 metros de mata ripária, e por outro lado ocorre um processo de assoreamento do leito do corpo hídrico, que se encontra em estágio avançado, como ficou constatada a presença de sedimentos dentro do igarapé e nesse ponto também fora observado a existência de águas de esgoto, sendo despejada para dentro do corpo hídrico (Figura 06). 
ANÁLISE GEO-HISTÓRICA DA OCUPAÇÃO HUMANA E IMPACTO AMBIENTAL NO IGARAPÉ GRANDE, EM BOA VISTA-RR.

\section{DUe REVISTA GEONORTE}

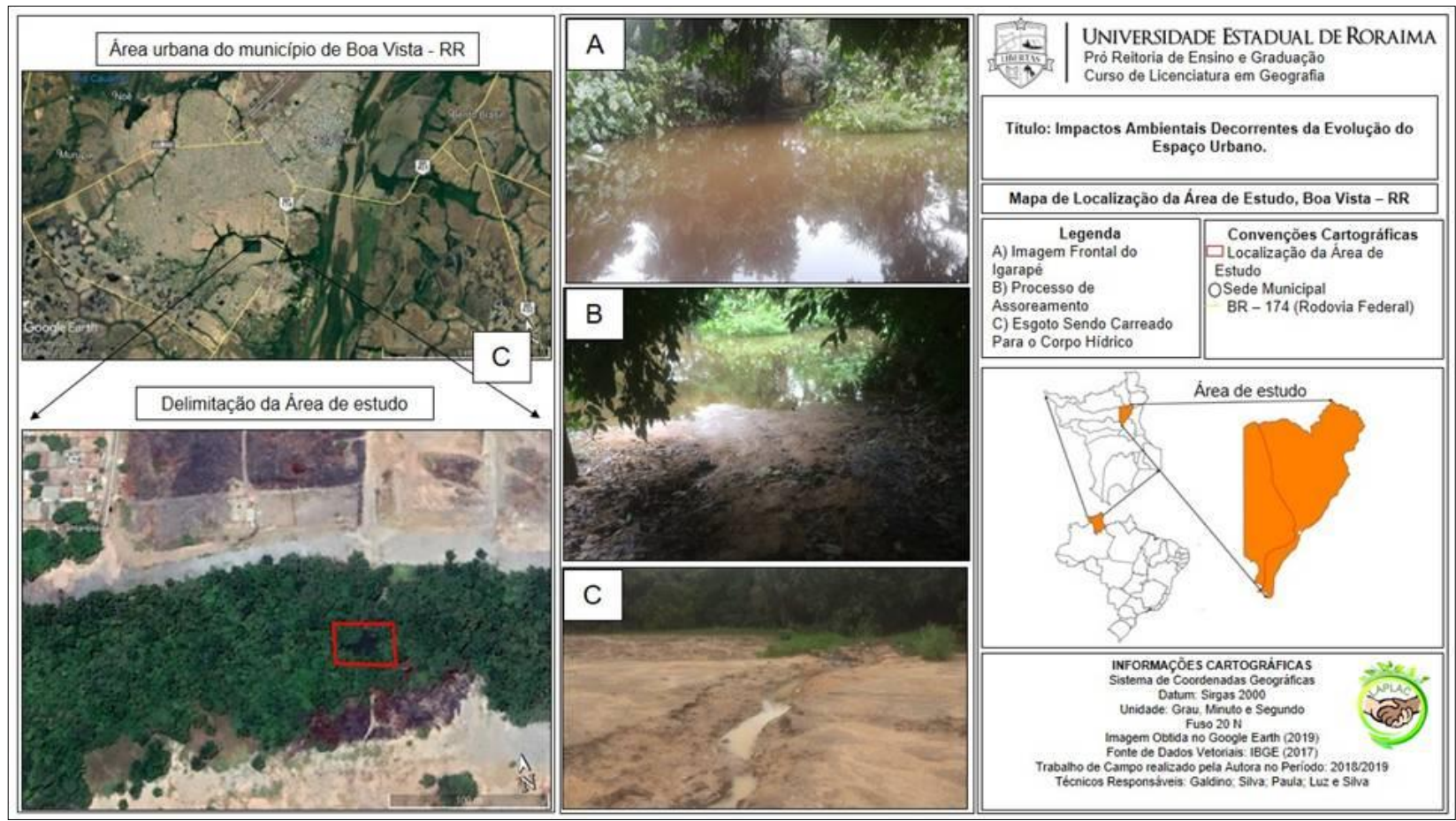

Figura 06: Carta imagem do P2.Fonte: Elaborada pelos autores, 2019.

Portanto, observou-se que em um curto período de tempo ocorreram grandes modificações na área estudada, e que o ambiente físico em decorrência da evolução/ocupação do espaço urbano revela a presença dos agentes promotores do espaço urbano, o que acelerou no processo de urbanização sem planejamento e amparo legal no plano diretor da cidade de Boa Vista-RR. Por fim, pode-se afirmar que as modificações ocorridas nos pontos 1 e 2, no decorrer de um ano, acarretou: inundações nas áreas ocupadas irregularmente; avanço na deposição de resíduos líquidos e sólidos (ocasionando a contaminação e poluição desse importante corpo hídrico); propagação de doenças de veiculação hídrica (dengue e malária); perca da ictiofauna e da vegetação primária e: perca da fauna terrestre, como: aves e mamíferos nativos da Amazônia.

\section{CONCLUSÃO}

O igarapé Grande está situado na zona oeste da cidade de Boa Vista-RR, nas divisas dos bairros São Bento e Centenário. Para tanto, esta área estudada é constituída por um arranjo hidrográfico com altimetria que varia de 60-80 metros, abarcando a Bacia Hidrográfica do Grande (BHG), a segunda maior bacia hidrográfica da cidade de Boa Vista, além de outros cursos d'água importantes como, o igarapé Paca (um de seus principais afluentes) que devido à expansão urbana foi alterado ambientalmente (GOMES et al., 2016). 
O igarapé Grande é um corpo hídrico com uma extensão de, aproximadamente, 8.550 $\mathrm{m}$ e largura média de $10 \mathrm{~m}$ e possui, cerca de, $1 \mathrm{~m}$ de profundidade e recebe as águas do igarapé do Paca formando uma microbacia que tem sua foz no rio Branco (SATELLES, 2011).

O igarapé Grande no decorrer das décadas, e através do processo de urbanização do município, vem sofrendo impactos ambientais devido a sua localização encontrar-se dentro da macha urbana. Um dos problemas mais enfrentados no que tange o igarapé, é sem sombra de dúvidas o avanço da ocupação irregular, a perda da mata ciliar e o despejo de esgotos.

Dessa maneira, o processo de urbanização se desenvolveu, de forma exponencial, comprometendo a área em estudo o que acarretou nas alterações no meio ambiente e que está mudando completamente a dinâmica natural desse relevante corpo hídrico urbano.

No que tange a pesquisa (in loco) foram analisadas as mudanças da biota, decorrentes do uso e ocupação do solo levando a crer que o processo de urbanização está afetando a dinâmica natural do corpo hídrico, em estudo.

Portanto, observa-se um rápido avanço das mazelas ambientais nas imediações dos perímetros analisados (P1 e P2) do igarapé Grande, onde tais problemáticas são protagonizadas por diversos fatores e atores que revelam um poder constituído que deveria exercer a efetiva fiscalização e a legalidade de proteger o meio ambiente.

\section{REFERÊNCIAS}

AGOSTINHO, J. Sustentabilidade Ambiental, Social e Econômica do Estado de Roraima. In: HOLANDA, E. C.; BESERRA NETA, L. C. (Org.). Geociências na PanAmazônia. Boa Vista: Editora UFRR, p. 249-272. 2016.

BRASIL. Constituição da República Federativa do Brasil de 1988. Disponível em: <http://www.planalto.gov.br/ccivil_03/constituicao/constituicao.htm>. Acesso em: 01.junho.2019.

BRAUDEL, F. Histoire et sciences sociales. Paris: Editions Flamarion, 1990.

CAVALCANTE MARTINS, O. D.; SANTOS, M. F.; SOUZA, V. Mapeamento das Áreas de Risco dos Recursos Hídricos do Bairro Paraviana, Boa Vista-RR. In: BESERRA NETA, L. C.; TAVARES JÚNIOR, S. S. (Org.). Contribuições à Geografia da Amazônia Setentrional. Boa Vista: Editora UFRR, 2014.

EVANGELISTA, R. A. O.; SANDER, C.; WANKLER, F. L. Estudo preliminar da distribuição pluviométrica e do regime fluvial da bacia do rio Branco, Estado de Roraima. In: SILVA, P. R. F.; OLIVEIRA, R. S. Roraima 20 anos: geografia de um novo Estado. Boa Vista: Editora da UFRR, 2008. 
ANÁLISE GEO-HISTÓRICA DA OCUPAÇÃO HUMANA E IMPACTO AMBIENTAL NO IGARAPÉ GRANDE, EM BOA VISTA-RR.

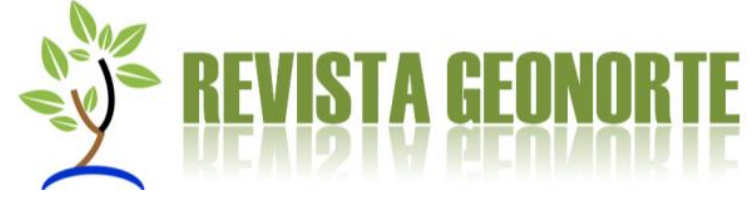

GALDINO, L. K. A. Sociedade, política, cultura e meio ambiente: subsídios ao planejamento socioambiental à comunidade indígena Boca da Mata, na terra indígena São Marcos - Roraima. Tese (Doutorado em Geografia - Programa de PósGraduação em Geografia), Universidade Federal do Ceará, Fortaleza, 2017a. 204 f.

GALDINO, L. K. A. Roraima: da colonização ao Estado (Tomo I). Boa Vista: Editora da UERR, 2017b.

GALDINO, L. K. A. Roraima: sociedade, política e meio ambiente (Tomo II). Boa Vista: Editora da UERR, 2018.

GOMES, M. L.; FARIZEL, S. R. S.; JÚNIOR, A. C. R. A. Geomorfologia ambiental como instrumento para o uso e ocupação do espaço urbano, Boa Vista-RR. In: XVIII ENCONTRO NACIONAL DE GEOGRÁFOS. São Luís, 2016. A contrução do Brasil: geografia, ação política e democracia. Disponívelem:http://www.eng2016.agb.org.br/resources/anais/7/1466771548_ARQUI VO GEOMORFOLOGIAAMBIENTALCOMOINSTRUMENTOPARAOUSOEOCUPAC AODOESPACOURBANOBOAVISTARR.pdf>. Acesso em: 01.junho.2018.

PAVANI, J. D.; MOURA, G. Panorama fotográfico urbanístico e arquitetônico de Boa Vista.Brasília: Gráfica Coronário, 2006.

RAFFESTIN, J. C. Por uma Geografia do poder. São Paulo: Ática, 1993.

RORAIMA. Guia turístico Roraima: ecológico, histórico e cultural. São Paulo: Empresa das Artes,2009.

SATELLES, J. L. Influência do lançamento do efluente da estação de tratamento de esgoto doméstico no lgarapé Grande em Boa Vista/RR, 2011. Diponível em: <http://bdtd.ufrr.br/tde_arquivos/4/TDE-2011-04-29T085617Z43/Publico/JoseLopesSatelles.pdf> Acesso em: 01 jun.2018.

SECRETARIA DE ESTADO DE PLANEJAMENTO E DESENVOLVIMENTO SEPLAN-RR. Panorama e vetores de desenvolvimento de Roraima: Volume IIII turismo, meio ambiente, zoneamento e recursos naturais. Boa Vista: SEPLAN-RR, 2013.

STAEVIE, P. M. Expansão urbana e exclusão social em Boa Vista - Roraima. OCULUM ENSAIOS 13. Campinas p. 68-87. Janeiro-Junho, 2011. Disponível em: $<$ https://seer.sis.puc-

campinas.edu.br/seer/index.php/oculum/article/viewFile/142/129>. Acesso em: 11 jan. 2018.

VALE, A. L. F. O "Ceará" em Roraima: migrações de cearenses -1980 a 1999. Jaboticabal: Funep, 2005. 
ANÁLISE GEO-HISTÓRICA DA OCUPAÇÃO HUMANA E IMPACTO AMBIENTAL NO IGARAPÉ GRANDE, EM BOA VISTA-RR.

VERAS, A. T. R. A produção do espaço urbano de Boa Vista - Roraima. Tese (Doutorado em Geografia - Programade Pós-Graduação em Geografia Humana), Universidade de SãoPaulo, São Paulo, 2009.235 f. 